\title{
New liquid chromatographic method for simultaneous quantification of Atovaquone and Proguanil with its active metabolite Cycloguanil in human plasma
}

\author{
Naresh Bejugam¹, Swapnil J Dengale'1, Raghavendra Shetty² and Prashant B Musmade ${ }^{1^{*}}$ \\ 'Department of Pharmaceutical Quality Assurance, Manipal College of Pharmaceutical Sciences, Manipal University, Manipal-576104 \\ ${ }^{2}$ Ecron Acunova, Kasturba Hospital Clinical Research center, Manipal-576104. INDIA.
}

\begin{abstract}
Objective: The aim of the present study is to develop HPLC method for simultaneousquantification of atovaquone and proguanil with its active metabolite cycloguanilin human plasma. Methodology: A specific and accurate highperformance liquid chromatographic method has been developed using Phenyl (150 $\times 4.6 \mathrm{~mm}, 5 \mu \mathrm{m}) \mathrm{column}$ maintained at $18{ }^{\circ} \mathrm{C}$. The separation was achieved using a mobile phase composed of phosphate buffer $\mathrm{pH}$ 7.2 and methanol (45:55\%). The mobile phase was maintained at flow rate of $0.8 \mathrm{~mL} / \mathrm{min}$. The analytes were monitored at $254 \mathrm{~nm}$ usingultra-violet detector. The plasma samples extractions was carried out using tert-Butyl Methyl Ether: Dichloromethane (80:20\% v/v) mixture. Tramadol was used as an internal standard (ISTD). Result: The developed method was validated as per US FDA guidelines and found to be highly specific, precise and accurate. Moreover, atovaquone, proguanil and cycloguanilwere stable in plasma at various stability conditions. Conclusion: The developed method is simple, economic, and can be used for quantification of said drugs human plasma samples.
\end{abstract}

Key words: Atovaquone, Cycloguanil, Proguanil, Human plasma, Bioanalysis, HPLC.

\section{INTRODUCTION}

Malaria is parasitic disease that involves high fevers, shaking chills, flu-like symptoms, and anemia caused by a parasite plasmodium, which infects red blood cells. The estimated annual mortality attributed to malaria ranges from 700000 to 2.7 million globally. ${ }^{1}$ Malaria is treated with anti-malarial drugs and by supportive measures. There are several classes of anti-malarial drugs available, chloroquine being one of them as a standard treatment option. Among all four types of plasmodium, in particular, plasmodium falciparum rapidly develops resistance against anti-malarials. This fact unavoidably entails poly-pharmacy for the treatment and prophylaxis of malaria to slow the emergence of resistance. The above cited fact is the primary reason for emergence of many fixed dose combinations in the treatment of malaria, Atovaquone (ATV) and Proguanil (PGN) being one of them. ${ }^{2-6}$

ATV is ahydroxyl-1,4-naphthoquinone[CAS: 95233-18-4], an analog of ubiquone with anti-pneumocystic activity. It acts by selectively affecting mitochondrial electron transport and pyridine biosynthesis in plasmodium species. PGN (chloroguanide) [CAS: 500-92-5] is a biguanide, a synthetic derivative of pyrimidine. PGN is converted into an active metabolite called Cycloguanil pamoate (CYG). It exerts its anti-microbial action by inhibiting parasitic dihydrofolate reductase enzyme and thereby blocks the biosynthesis of purines and pyrimidines, which are essential for DNA synthesis and cell multiplication of plasmodium. There are certain scientific facts, which make ATV (250 mg) plus PGN, a popular fixed dose combination Firstly, the combination has
Submission Date : 04-04-14 Revision Date : :21-10-14 Accepted Date $\quad$ :26-11-14

DOI: $10.5530 /$ ijper.48.4s.11 Correspondence Address Prof. Prashant B. Musmade,

Department of Pharmaceutical Quality Assurance, Manipal College of Pharmaceutical Sciences,

Manipal University, Manipal-576104, INDIA.

E-mail: prashant.musmade@ gmail.com

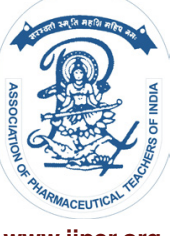

www.ijper.org 
$100 \%$ protective efficacy. Secondly, there is no recorded adverse drug event even in chemo-suppressed patients with this combination. Thirdly, simple administration with single daily dose increases the patient compliance. ${ }^{3,5,7}$ The Therapeutic Drug Monitoring (TDM) of ATV plus PGN requires a fast, reliable and validated analytical method for estimation in human plasma. The complexity of dosage forms including the presence of multiple drug entities pose challenge during the development of assay procedure. The combination of ATV plus PGN is efficient in controlling the malarial infection. The PGN undergoes the CYP P450 metabolism and forms the active metabolite CYG. It is necessary to estimate the active metabolites with parent compunds.

Literature survey revealed that there are plenty methods have been published for estimation of either ATV or PGN in biological matrix. All methods except one estimate either ATV or PGN and its metabolite CYG. Only one method reported by Berggrist et al. for simultaneous estimation of ATV, PGN and CYG in single run. ${ }^{8}$ This method used mixed mode column for separation of three analytes. The common problem with mixed mode column is that, optimization of chromatographic parameters with different buffer ratios usually turn out to be cumbersome, as it requires to optimize the concentration of sodium and potassium ions into mobile phase to achieve good retention and moreover mixed mode column is not usually available and comes under specialty requirement in analytical lab. These facts disqualify aforementioned method on the grounds of simplicity and cost effectiveness. Many methods also utilized the technique of dry spot analysis for extraction of analytes, which require much less matrix volume for processing and further analysis. ${ }^{9-11}$ Several LC-MS/MS methods also have been reported for quantification of ATV or PGN and CYG, which are more specific and sensitive. ${ }^{12,13}$ However these methods are not affordable for most laboratories because of their specialty requirements and high equipment costs, moreover no LC-MS/ MS method has been reported for simultaneous estimation of ATV, PGN and CYG in one single run so far. Under the scope of this view, the aim of our research work was to develop and validate alternative, simple and cost-effective method for simultaneous estimation of ATV, PGN and CYG in single run.

\section{MATERIALS AND METHODS}

\section{Chemicals and Reagents}

Micronized Atovaquone (99.80\%) (Figure 1a), Proguanil hydrochloride $(99.49 \%)$ (Figure 1b) and Cycloguanil hydrochloride $(98.00 \%)$ (Figure 1c) were purchased from USV limited (Mumbai, Maharashtra, India), Varda biotech private limited (Hyderabad, Andhra Pradesh India) and Torrent research center (Ahmedabad, Gujarat, India) respectively. Tramadol hydrochloride $(100.40 \%)$ (Figure 1d) was selected as an internal stan-
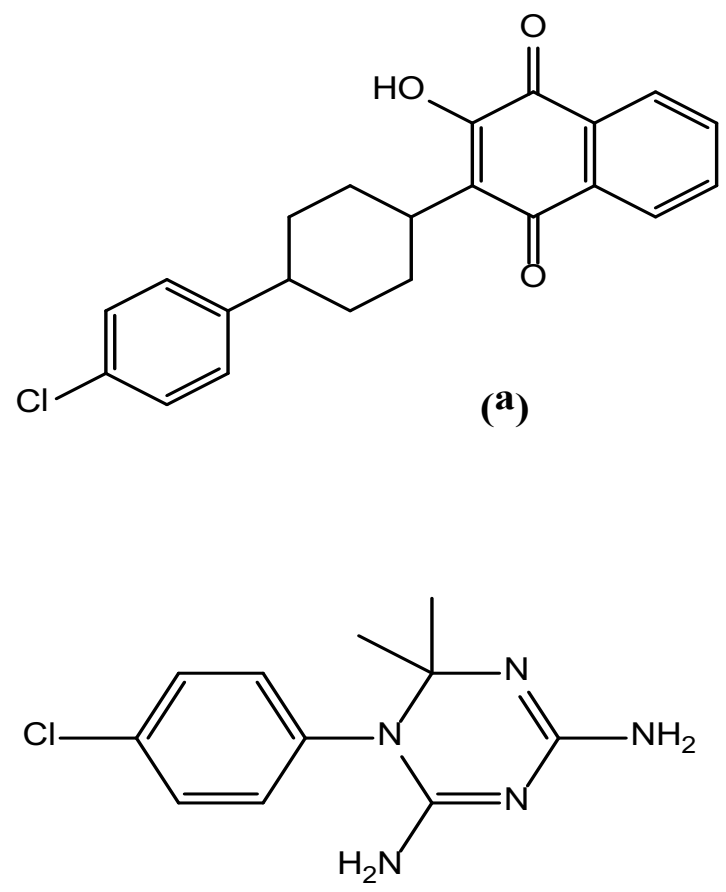

(c)

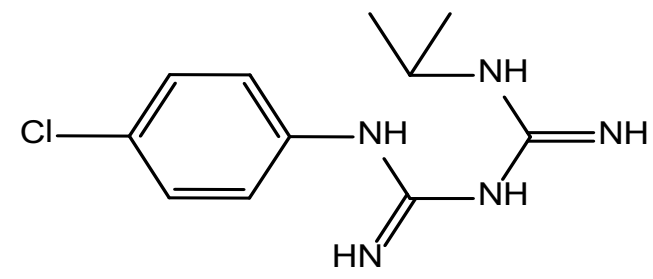

(b)

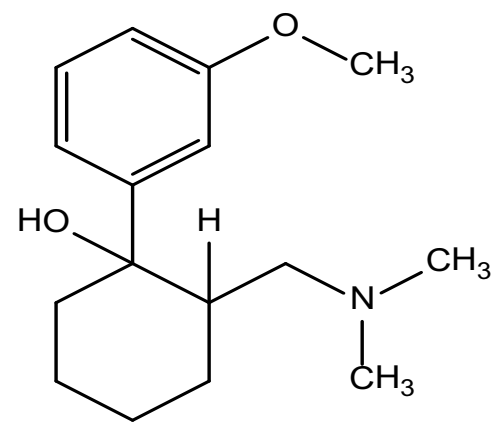

(d)

Figure 1: Structures of Atovaquone (a), Proguanil (b), Cycloguanil (c) and Tramadol(d) 
dard, which was purchased from Jubilant Organosys (New Delhi, India). Analytical grade reagents such as potassium dihydrogen phosphate, potassium hydroxide and sodium bicarbonate were obtained from SD fine chemicals (Mumbai, Maharashtra, India). HPLC grade reagents such as methanol, methyl tertiary butyl ether (TBME) and dichloromethane (DCM) were purchased from LabScan. Millipore water $(0.22 \mu \mathrm{m}$ membrane filtered) was produced in the laboratory by Millipore system (Model: Direct-Q ${ }^{\circledR} 3$ water purification system) Millipore Corporation, (Billerica, MA, U.S.A.).

\section{Instrumentation}

The analysis was carried out on a Shimadzu LC-10 series chromatographic system (Shimadzu Corporation, Kyoto, Japan) consisting of a SCL-10A controller unit, DGU-2A degasser unit, a LC-20AD quaternary gradient pump, SIL10AD autosampler with SPD-20A UV detector. System control, data acquisition and processing were performed with a PC-Pentium IV Processor personal computer operated with Microsoft Windows XP and Shimadzu LC solution 1.24 SP1 software. Standard substances were weighed on Sartorius analytical balance. A glass vacuum-filtration apparatus (Alltech Associates) was employed for the filtration of buffer solution using $0.45 \mu \mathrm{m}$ filter obtained from Pall Life Sciences (Bangalore, Karnataka, India). Degassing of the mobile phase was performed by sonication in Oscar Micro clean-103 Ultrasonic bath. Thermo 995-Forma86C freezer (Thermo electron corporation, USA) was used to store the plasma samples. A model Genie-2 Spinix vortex mixer, a Heraeus refrigerated centrifuge (Thermo electron corporation, USA) and TurboVap LV Evaporator (Caliper Life Sciences, Hopkinton, MA, USA) were employed for sample pre-treatment.

\section{Chromatographic conditions}

The chromatographic separation was achieved using a Thermo phenyl $(150 \times 4.6 \mathrm{~mm}$ ID $\times 5 \mu \mathrm{m})$ column with mobile phase comprising of $15.0 \mathrm{mM}$ potassium dihydrogen phosphate buffer, $\mathrm{pH} 7.2(45 \%)$ and methanol $(55 \%)$. The flow rate was $0.8 \mathrm{~mL} / \mathrm{min}$ and column temperature was set to $18^{\circ} \mathrm{C}$. Ultra-violet measurements were done at $254 \mathrm{~nm}$ wavelength with total run time of $12.5 \mathrm{~min}$.

\section{Preparation of standard solutions}

ATV, CYG and PGN were dissolved in methanol to prepare a primary stock solution at a concentration of $1000 \mu \mathrm{g} / \mathrm{mL}$. Corrections to the theoretical concentration were performed according to the degree of standard substance impurities. The mixed intermediate stock of these drugs was prepared by approximately diluting the stock solutions of ATV, CYG and PGN to get a concentration of $600.0 \mu \mathrm{g} / \mathrm{mL}, 45.0 \mu \mathrm{g} / \mathrm{mL}$, and $22.4 \mu \mathrm{g} / \mathrm{mL}$ respectively.

The mixed intermediate stock was used to prepare spiking stock solution for the construction of nine point calibration curve for $\operatorname{ATV}(4687.5,9375.0,15000.0$, $30000.0, \quad 60000.0, \quad 120000.0, \quad 180000.0, \quad 240000.0$, $300000.0 \mu \mathrm{g} / \mathrm{ml})$; $(351.5,703.1,1125.0,2250.0,4500.0$, 9000.0, 13500.0, 18000.0, 22500.0 $\mu \mathrm{g} / \mathrm{ml})$ PGN and Cycloguanil (175.0, 350.0, 560.0, 1120.0, 2240.0, 4480.0, 6720.0, 8960.0, $11200.0 \mu \mathrm{g} / \mathrm{ml}$ ). QC samples at three different levels for ATV $(14.06 \mu \mathrm{g} / \mathrm{ml}, 150.00 \mu \mathrm{g} / \mathrm{ml}$ and $270.00 \mu \mathrm{g} / \mathrm{ml})$, for PGN $(1.05 \mu \mathrm{g} / \mathrm{ml}, 11.25 \mu \mathrm{g} / \mathrm{ml}$, $20.25 \mu \mathrm{g} / \mathrm{ml})$ and for CYG $(0.525 \mu \mathrm{g} / \mathrm{ml}, 5.60 \mu \mathrm{g} / \mathrm{ml}$ and $10.08 \mu \mathrm{g} / \mathrm{ml}$ ) were prepared by taking appropriate volumes of mixed intermediate stock.

Working stock solutions of ATV, CYG and PGN were prepared using a mixture of methanol-water, 50:50\% $\mathrm{v} / \mathrm{v}$ (diluent). The ISTD working solutions were prepared in a similar manner, providing finally a plasma concentration of $14.3 \mu \mathrm{g} / \mathrm{mL}$. The intermediate stock solutions were prepared weekly, while working stock solutions used for the calibration curves were prepared daily. Stock solutions, intermediate stock solutions and spiking stock solutions were kept at $4^{\circ} \mathrm{C}$ and remained stable for at least 7 days.

Calibration standards in plasma for ATV $(93.75,187.50$, 300.00 , 600.00, 1200.00, 2400.00, 3600.00, 4800.00, $6000.00 \mathrm{ng} / \mathrm{mL})$, CYG (3.50, 7.00, 11.20, 22.40, 44.80, 89.60, 134.40, 179.20, $224.00 \mathrm{ng} / \mathrm{mL})$, PGN (7.03, 14.06, $22.50,45.00,90.00,180.00,270.00,360.00,450.00 \mathrm{ng} /$ $\mathrm{mL}$ ) were prepared by spiking $686.00 \mu \mathrm{L}$ blank human plasma with $14.00 \mu \mathrm{L}$ of mixed working stock solutions of ATV, CYG and PGN as percentage of spiking was $2 \%(\mathrm{v} / \mathrm{v})$.

Quality Control (QC) samples at four different levels were independently prepared at LOQ-QC with same concentration as the lowest non-zero standard, LQC lower quality control sample, MQC middle quality control sample and HQC higher quality control sample of ATV, CYG and PGN in the same manner. The quality control samples were prepared from a stock solution that was different from the one used to generate standard curve samples. These quality control samples were used to investigate intra- and inter-run variations.

\section{Sample preparation}

$700.0 \mu \mathrm{L}$ of blank plasma or standard spiked plasma was taken in $15.00 \mathrm{~mL}$ glass centrifuge tube followed by addition of $10.00 \mu \mathrm{L}$ of tramadol (ISTD) of 1.0 $\mathrm{mg} / \mathrm{mL}$ and vortexed for $15 \mathrm{sec}$. Further, $700.00 \mu \mathrm{L}$ of 5.0 M Sodium hydroxide solution was added and vortexed for 30sec. Subsequently, total $1400.00 \mu \mathrm{L}$ sample was extracted with $5.500 \mathrm{~mL}$ of extracting solvent 
TBME:Dichloromethane (80:20\% v/v) mixture. The mixture was vortexed again for $15 \mathrm{~min}$ and centrifuged at $3500 \mathrm{rpm}$ for $10 \mathrm{~min}$. The supernatant organic phase was collected and evaporated to dryness in a water bath at $40^{\circ} \mathrm{C}$ under a gentle stream of nitrogen. The dried residue was reconstituted with $100.0 \mu \mathrm{L}$ of diluent and vortexed for $1 \mathrm{~min}$ and a volume of $25.0 \mu \mathrm{L}$ was injected into the HPLC system.

\section{Method validation ${ }^{14}$}

\section{Selectivity}

Selectivity was performed to ensure that the bioanalytical method was able to measure and differentiate the analytes in the presence of components that may be expected to be present (metabolites, impurities, degradants or matrix components). It was evaluated by injecting extracted blank human plasma of six different sources and comparing the response of extracted LLOQ with ISTD. There should be no interfering peak present either at drug or at ISTD retention time. If the peak was present then, its response should be $\leq 20 \%$ of mean extracted LLOQ area for analyte(s) and 5\% for mean extracted ISTD area.

\section{Linearity (calibration curve)}

A calibration (standard) curve is the relationship between instrument response and known concentrations of the analyte. Linearity of the method was assessed by constructing five calibration curves, each with one blank plasma (matrix sample processed without ISTD), zero sample (matrix sample processed with ISTD) and nine non-zero samples covering the range 93.75-6000.00 ng/mL for ATV, 3.50-224.00 ng/mL for CYG and $7.00-450.00 \mathrm{ng} / \mathrm{mL}$ for PGN. Calibration curves were constructed by linear least-squares regression analysis, plotting of peak-area ratios (drug /ISTD) versus the drug concentrations. Weighing factor $1 / \mathrm{x}^{2}$ was used for the determination of curve fitting. The calibration model was accepted, if (a) coefficient of correlation was greater than or equal to 0.9800 ; (b) residuals were within $\pm 20 \%$ at the lower limit of quantification and within $\pm 15 \%$ at all other calibration levels; (c) no two consecutive calibration curve standards fail to meet the above acceptance criteria; and (d) at least $2 / 3$ of the standards meet this criterion.

\section{Detection \& Quantification limit (Sensitivity)}

The detection limit (LOD) is defined as the lowest concentration level resulting in a peak area of three times the baseline noise. The limit of quantification (LLOQ) was determined as the lowest concentration on the standard calibration curve that provided a peak area with a signal-to-noise ratio higher than 5 with a precision $20 \%$ and accuracy of $80-120 \%$ of its nominal value.

\section{Assay precision \& Accuracy}

The accuracy of an analytical method describes the closeness of mean test results obtained by the method to the true value (concentration) of the analyte. The precision of an analytical method describes the closeness of individual measures of an analyte when the procedure is applied repeatedly to multiple aliquots of a single homogeneous volume of biological matrix. As per the US-FDA guideline, accuracy and precision were done at four concentration levels viz LOQ-QC, LQC, MQC and HQC. Six determinations were made at each quality control level on three different days. The accuracy (\%bias) was calculated from the mean value of observed concentration (Cobs) and the nominal concentration (Cnom) as follows

$$
\text { Accuracy }(\% \text { Bias })=\frac{\text { Concentration found }}{\text { Nominal Concentration }} \times 100
$$

The percent coefficient of variation, $\% \mathrm{CV}$ was calculated from the observed concentrations as follows:

$\% C V=\frac{\text { Standard diviation }}{\text { Mean }} \times 100$

The accuracy determined at each concentration level must be within $\pm 15 \%$ of the respective nominal value except at LOQ-QC where it must be within $\pm 20 \%$ of the nominal value. The precision around the mean value must not exceed $15 \%$ of the $\% \mathrm{CV}$ except for LOQ-QC where it must not exceed $20 \%$ of the $\% \mathrm{CV}$.

\section{Recovery}

Recovery pertains to the extraction efficiency of a bioanalytical method within the limits of variability. Recovery of analytes was evaluated by comparing the mean peak areas of the three extracted LQC, MQC, and HQC samples to mean peak areas of three reference solutions (Unextracted). Recovery of ISTD was evaluated by comparing the mean peak areas of extracted samples to mean peak areas of reference solutions (unextracted) of the same concentration.

Recovery $=\frac{\text { Peak area response of extracted samples at } \mathrm{LOC}, M Q C, H Q C}{\text { Peak area response of unextracted amples at } \mathrm{LQC}, \mathrm{MQC}, \mathrm{HQC}}$

\section{Stability studies}

\section{Stock solution stability}

The drug stability is a function of the storage conditions and the chemical properties of the drug. Stock solution stability was performed at room temperature for $6.0 \mathrm{~h}$ and at 2 to $8^{\circ} \mathrm{C}$ for 7 days. Stock solution stability was assessed by comparing freshly prepared samples of analyte(s) and ISTD with that of stability samples at MQC level by performing five injections of each. Mean percentage change was calculated for both analyte(s) 
and ISTD. Stock solution of analyte(s) and ISTD is deemed stable if mean percentage change of ISTD and analyte(s) was within $\pm 10 \%$.

\section{Stability in matrix}

Stability studies on analyte(s) which include bench top, freeze and thaw, and long term have been evaluated during validation.

\section{Bench top stability}

Six replicates of LQC and HQC in biological matrix were withdrawn and thawed unassisted at room temperature and kept unprocessed for $7 \mathrm{~h}$ (stability samples). After $7 \mathrm{~h}$ fresh calibration curve was prepared with one set of low and high QC samples (comparison samples). Both comparison samples and stability samples were processed and analyzed in single run.

\section{Freeze thaw stability}

Freeze thaw stability in plasma was assessed by analyzing six replicates of LQC and HQC samples after three freeze and thaw cycles. Samples were stored at the intended storage temperature for $24 \mathrm{~h}$ and thawed unassisted at room temperature. When completely thawed, the samples were refrozen for 12 to $24 \mathrm{~h}$ under the same conditions. The freeze-thaw cycle was repeated two more times, samples were then analyzed on the third cycle. Calibration standards and quality control samples (comparison samples) and stability samples were processed and analyzed in single run.

\section{Long term stability}

Six replicates of LQC and HQC in biological matrix were withdrawn from deep freezer $\left(-70^{\circ} \mathrm{C}\right)$ after 90 days and thawed at room temperature (stability samples). Fresh calibration was prepared with six replicates of low and high QC samples (comparison samples). Both comparison samples and stability samples were processed and analyzed in single run.

Analyte(s) were deemed stable in matrix if mean percentage change of analyte(s) was within $\pm 15 \%$.

Mean $\%$ change $=\frac{\text { Calculated concentration of stability samples }}{\text { Calculate concentration of comparison samples }}-1$ 100 Calculate concentration of comparison samples

\section{RESULTS AND DISCUSSION}

\section{Selection of chromatographic parameters}

Due to the difference between $\log \mathrm{P}$ values of ATV (5.8) and CYG (1.0), which is in particular very high, the selection of either reversed phase $\mathrm{C}_{18}$ column or normal phase column is crucial. Selection of reversed phase thermo Betasil $\mathrm{C}_{18}$ column was tried with $50: 50 \% \mathrm{v} / \mathrm{v}$ aqueous methanol as a mobile phase which was resulted in very long retention time for ATV and less retention for CYG. The trial with Genesis $\mathrm{C}_{8}$ with intermediate polar stationary phase was taken with the intent to negotiate the considerable $\log \mathrm{P}$ difference between ATV and CYG. The peak shape of analytes was improved and retention was increased with ATV eluting almost at retention time $16 \mathrm{~min}$. Further in order to decrease the total chromatographic run time thermo Betasil phenyl column was tried. Owing to the intermediate polarity and $\square-\square$ electron interaction between analyte and phenyl stationary phase, all three analytes were retained on thermo Betasil phenyl column with run time reduced to $12.5 \mathrm{~min}$. The potassium dihydrogen phosphate buffer was used due to its buffer capacity over wide range of $\mathrm{pH}$. Upon increasing the $\mathrm{pH}$ of the buffer from 4.5 through 6 to 7.2, the retention time of PNG and CYG were increased whilst retention for ATV was decreased. Buffer methanol in the ratio of $40: 60 \mathrm{v} / \mathrm{v}$

was tried as mobile phase, which was resulted in poor resolution between CYG and PGN, further the organic phase was reduced to $55 \%$ in order to increase the resolution between CYG and PGN. The retention time of ATV was found to be dependent on the proportion of organic content in the mobile phase. Upon decreasing of organic content in mobile phase, retention time of ATV was increased. In nutshell, the optimized mobile phase composition for proper resolution between analytes was $45: 55 \%(\mathrm{v} / \mathrm{v})$ of potassium dihydrogen phosphate $\mathrm{pH} 7.2$ methanol.

\section{Selection of extraction technique}

Due to the high to intermediate polarity of analytes, solid phase extraction was thought to be a good sample clean up technique. By using OASIS HLB i.e. hydrophilic lipophilic balance cartridges, which has the capability to retain analytes ranging from low polarity to high polarity was tried. The recovery of PGN was found good, but interference was observed at the retention time of ATV. Further by keeping in mind the high cost associated with solid phase extraction, the optimization efforts were abandoned. The conventional LiquidLiquid Extraction (LLE) technique was given a priority for sample clean-up step. But the problem faced with LLE was, again the wide variation in polarity values for analytes in question, which entailed the approach of using cocktail of two different extractions solvent to manipulate the final polarity of resulting extraction solvent. TBME was used to decrease the polarity, while DCM was used for otherwise purpose. Different ratios of TBME and DCM were tried to get good, consistent recovery, and further to avoid any interference on retention time of analytes. The combination of TBME : DCM (80:20\% v/v) was finalized as an extraction solvent (Table 1). 
Table 1: Effect of extraction solvent and buffer on recovery of atovaquone, cycloguanil and proguanil in human plasma.

\begin{tabular}{|c|c|c|c|c|}
\hline \multirow[t]{2}{*}{ Extraction Solvent } & \multirow[t]{2}{*}{ Buffer } & \multicolumn{3}{|c|}{ Recovery } \\
\hline & & Atovaquone & Cycloguanil & Proguanil \\
\hline \multirow{7}{*}{$\begin{array}{l}\text { Combination of } \\
\text { TBME:DCM } \\
(50: 50 \%)\end{array}$} & $\mathrm{KH}_{2} \mathrm{PO}_{4}(0.5 \mathrm{M})$ & $52 \%$ & $15 \%$ & $65 \%$ \\
\hline & $\mathrm{NaOH}(0.5 \mathrm{M})$ & $55 \%$ & $40 \%$ & $70 \%$ \\
\hline & $\mathrm{KOH}(0.5 \mathrm{M})$ & $30 \%$ & $20 \%$ & $68 \%$ \\
\hline & $\mathrm{Na}_{2} \mathrm{CO}_{3}(0.5 \mathrm{M})$ & $50 \%$ & $25 \%$ & $65 \%$ \\
\hline & $\mathrm{NaHCO}_{3}(0.5 \mathrm{M})$ & $55 \%$ & $20 \%$ & $65 \%$ \\
\hline & $\mathrm{NaOH}(1 \mathrm{M})$ & $50 \%$ & $42 \%$ & $80 \%$ \\
\hline & $\mathrm{NaOH}(5 \mathrm{M}) 55 \%$ & $65 \%$ & $83 \%$ & $94 \%$ \\
\hline \multicolumn{5}{|c|}{ Combination of TBME:DCM } \\
\hline 60.40 & $\mathrm{NaOH}(5 \mathrm{M}$ & $65 \%$ & $75 \%$ & $88 \%$ \\
\hline $70: 30$ & $\mathrm{NaOH}(5 \mathrm{M}$ & $72 \%$ & $78 \%$ & $90 \%$ \\
\hline $80: 20$ & $\mathrm{NaOH}(5 \mathrm{M})$ & $83 \%$ & $78 \%$ & $90 \%$ \\
\hline
\end{tabular}

The Pka values for ATV, CYG and PGN are 8.23, 10.12 and 9.24 respectively. Since all three Pka values are lying towards the basic side, the basic buffers were chosen to optimize the recovery of analytes. Potassium dihydrogen orthophosphate $\left(\mathrm{KH}_{2} \mathrm{PO}_{4}\right)$, sodium hydroxide $(\mathrm{NaOH})$, potassium hydroxide $(\mathrm{KOH})$, sodium carbonate $\left(\mathrm{Na}_{2} \mathrm{CO}_{3}\right)$ and sodium bicarbonate $\left(\mathrm{NaHCO}_{3}\right)$ with $7.00 \mu \mathrm{L}$ of $0.5 \mathrm{M}$ concentration were tried initially by keeping TBME:DCM ratio 50:50\% v/v. Amongst all buffers, $\mathrm{NaOH}$ was further chosen due to satisfactory recovery of analyte i.e 55\% ATV, 40\% CYG and 70\% PGN. In order to increase the recovery, buffer strength was increased from 0.5 to $1.0 \mathrm{M}$ initially and to $5.0 \mathrm{M}$ eventually. Due to an interesting finding of increased in recovery of all three analytes after increasing the buffer strength, $5.0 \mathrm{M}$ buffer strength with highest recovery at TBME:DCM 50:50\% v/v was taken up for further development. To increase the recovery further, changes in the proportion of TBME and DCM were tried. Increase in the proportion of TBME was followed by increase in the recovery of ATV and PGN, though the recovery of CYG was fallen. The recovery of CYG was found $83 \%$ and $78 \%$ at $50 \%$ and $80 \%$ of TBME proportion respectively. It is evident that fall in the recovery of CYG is not significant in light of the significant increase in the recovery of other two analytes at 80:20\% $\mathrm{v} / \mathrm{v}$ proportion and hence the TBME:DCM $(80: 20 \%$ $\mathrm{v} / \mathrm{v})$ proportion was finalized for extraction.

\section{Method validation}

\section{Selectivity}

The developed method was found selective as no significant interference observed at respective retention

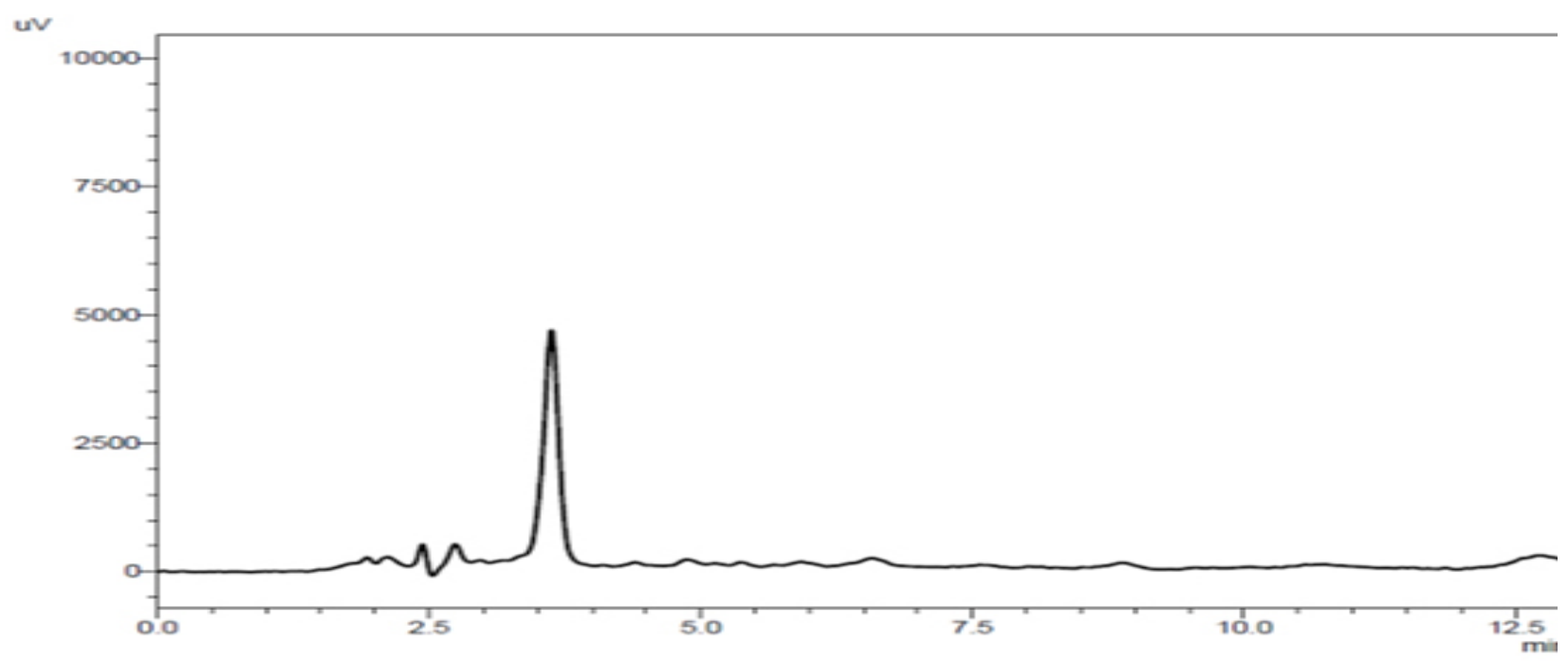

Figure 2: Representative chromatogram of blank human plasma 


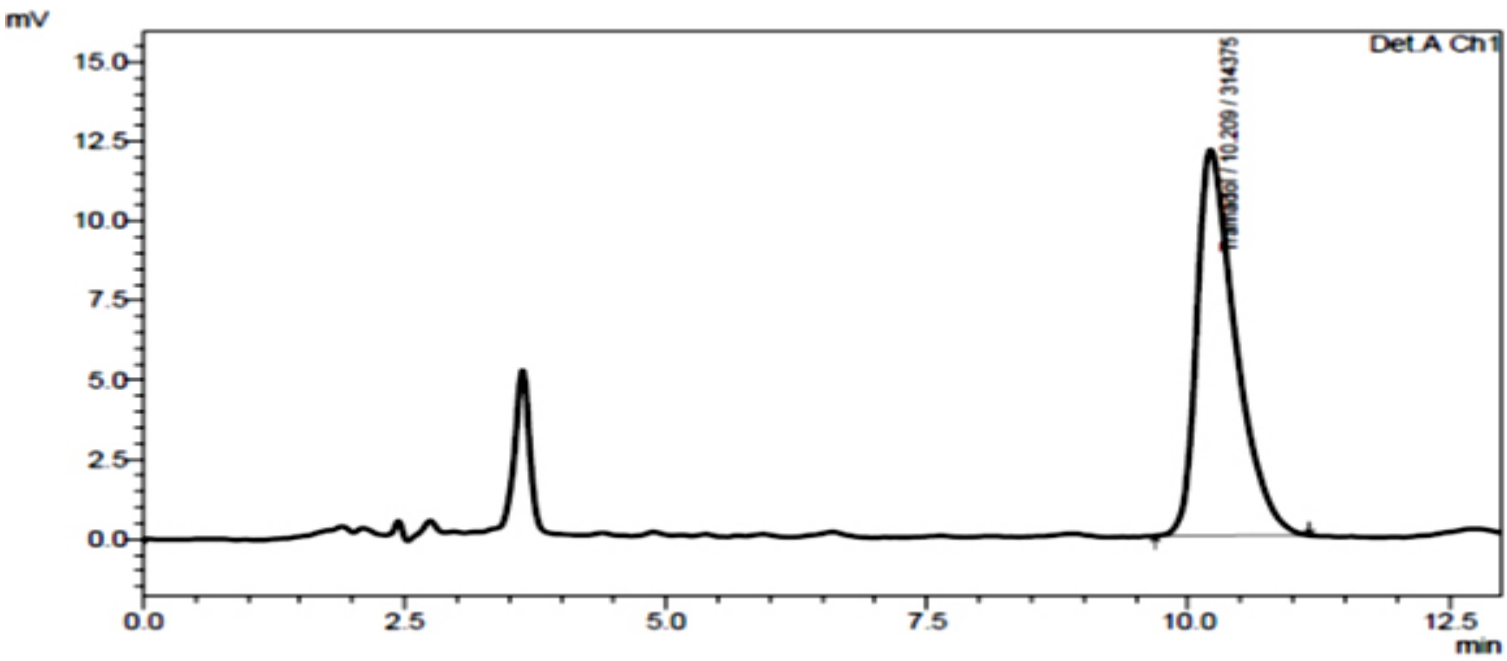

Figure 3: Representative chromatogram of blank human plasma spiked with internal standard

$\mathrm{mV}$

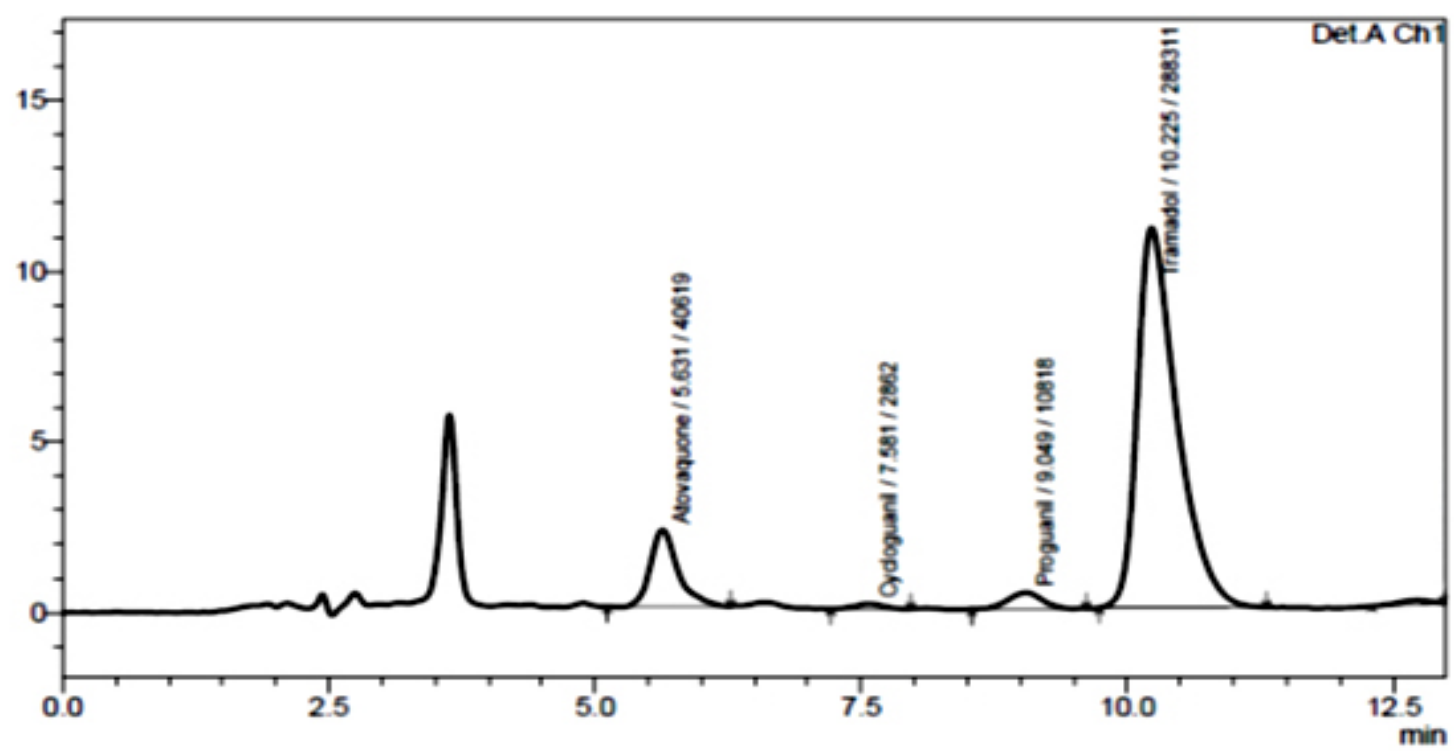

Figure 4: Representative chromatogram of blank human plasma spiked at LLOQC level of atovaquone, Proguanil, Cycloguanil and internal standard

time of ATV, CYG and PGN from the plasma. The representative chromatograms of extracted blank human plasma and plasma spiked with ISTD are shown in figure 2 and figure 3 respectively.

\section{Linearity}

Calibration curves were found linear for ATV over 93.75$6000 \mathrm{ng} / \mathrm{mL}$, CYG over 3.5-224 ng/mL and PGN over 7.03-450 ng/mL. The $\mathrm{r}^{2}$ between $0.9854-0.9916$ for ATV, was 0.9864-0.9943 for CYG and 0.9841-0.9964. for PGN All the calibration levels nominal concentration and $\% \mathrm{CV}$ was within the limit.

\section{Detection and quantification limit}

In alignment with the criteria for clinical and preclinical bioequivalence studies, which demand LLOQ of bio- assay to be at least $10 \%$ of the Cmax or five $t_{1 / 2}$ of the drug under consideration, whichever is smallest, the LLOQs of present method were found out to be 93.75, 3.50 and $7.03 \mathrm{ng} / \mathrm{mL}$ for the ATV, CYG and PGN respectively (Figure 4$)$. The LOD considering the signal to noise ratio of 3:1, was estimated to be 5.0, 2.0 and 5.0. $\mathrm{ng} / \mathrm{mL}$ for the ATV, CYG and PGN respectively.

\section{Assay precision and accuracy}

To determine intra-day accuracy and precision, six replicate analyses were carried out at each of the four quality control levels. The inter-day accuracy and precision were assessed by the analysis of six samples (two samples per day at each level of four QC samples), back calculated from freshly spiked calibration curves for the 


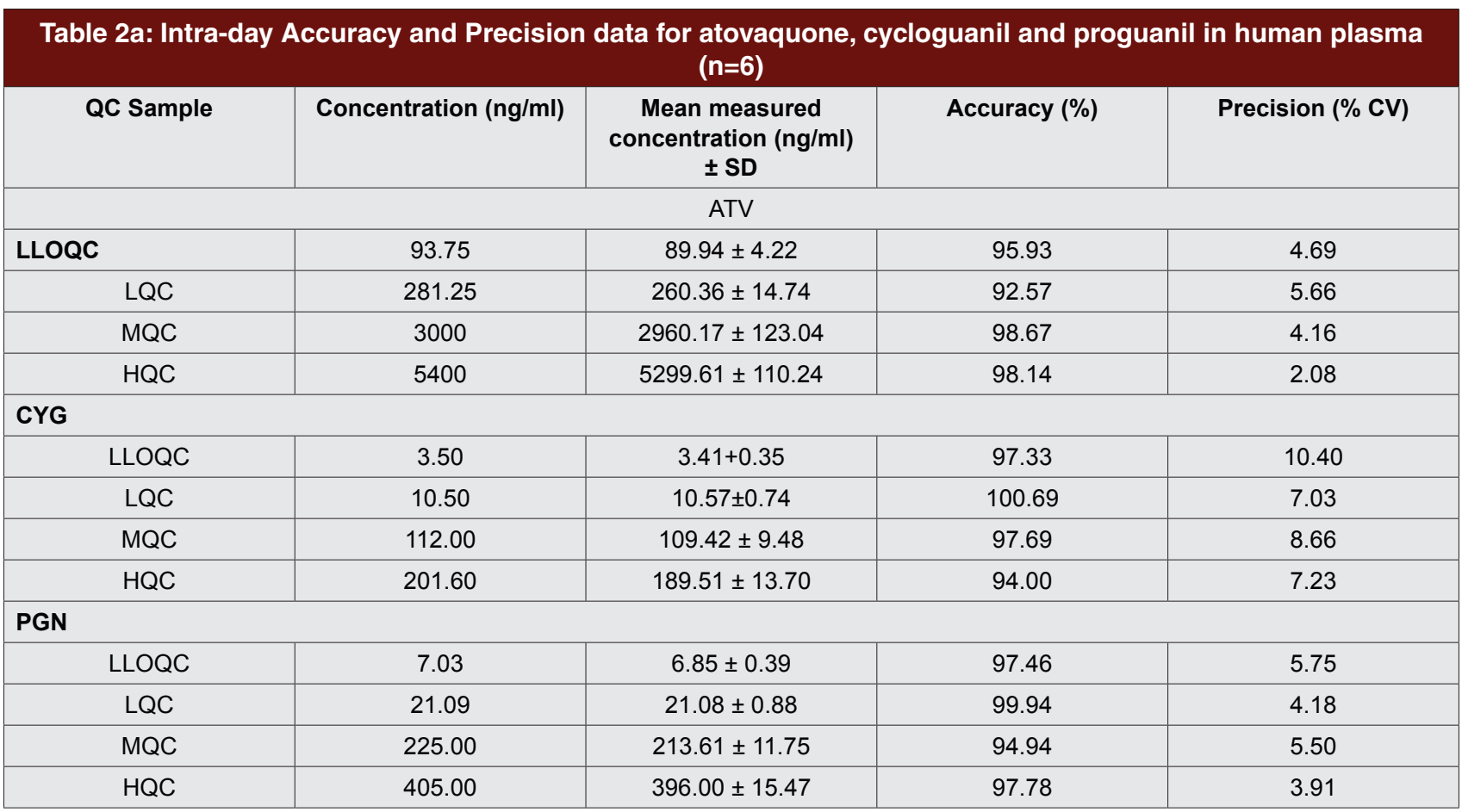

\begin{tabular}{|c|c|c|c|c|}
\hline QC Sample & Concentration (ng/ml) & $\begin{array}{c}\text { Mean measured } \\
\text { concentration }(\mathrm{ng} / \mathrm{ml}) \\
\pm \mathrm{SD}\end{array}$ & Accuracy (\%) & Precision (\% CV) \\
\hline \multicolumn{5}{|l|}{ ATV } \\
\hline LLOQC & 93.75 & $94.71 \pm 6.86$ & 101.03 & 7.24 \\
\hline LQC & 281.25 & $277.72 \pm 20.90$ & 98.75 & 7.52 \\
\hline MQC & 3000 & $2914.17 \pm 193.81$ & 97.14 & 6.65 \\
\hline HQC & 5400 & $5386.43 \pm 359.16$ & 99.75 & 4.57 \\
\hline \multicolumn{5}{|l|}{ CYG } \\
\hline LLOQC & 3.50 & $3.55 \pm 0.28$ & 101.30 & 7.83 \\
\hline LQC & 10.50 & $10.12 \pm 0.67$ & 96.33 & 6.59 \\
\hline MQC & 112.00 & $111.81 \pm 7.02$ & 99.83 & 6.28 \\
\hline HQC & 201.60 & $198.62 \pm 15.66$ & 98.52 & 7.89 \\
\hline \multicolumn{5}{|l|}{ PGN } \\
\hline LLOQC & 7.03 & $6.93 \pm 0.40$ & 98.62 & 5.83 \\
\hline LQC & 21.09 & $21.29 \pm 1.03$ & 100.92 & 4.84 \\
\hline MQC & 225.00 & $217.18 \pm 12.87$ & 96.52 & 5.93 \\
\hline HQC & 405.00 & $396.62 \pm 21.22$ & 97.93 & 5.35 \\
\hline
\end{tabular}

analyte on three different days. The intra-day and interday accuracy and precision values of the assay method are shown in (Table $2 \mathrm{a}$ and $2 \mathrm{~b}$ ) respectively. The precision of the method was calculated as coefficient of variation $(\% \mathrm{CV})$ of the concentrations determined in all replicates. The intra-day $\% \mathrm{CV}$ values were below $3.63 \%, 10.40 \%$ and $5.75 \%$ for ATV, CYG and PGN respectively. All inter-day $\% \mathrm{CV}$ were below $7.89 \%$. The accuracies were determined by comparing the mean calculated concentration with the spiked target concentration of the quality control samples. The inter-day accuracies for all three analytes were found to be within $96.33 \%$ to $101.30 \%$ of the target values. Whilst intraday accuracies for all three analytes were found to be within $92.57 \%$ to $100.69 \%$.

\section{Recovery}

Mean recoveries across the QC levels were found 88.15, 87.20 and $97.52 \%$ for ATV, CYG and PGN respec- 
Table 3. Mean percentage recovery for atovaquone, cycloguanil and proguanil in human plasma $(\mathrm{n}=6)$

\begin{tabular}{|l|c|c|c|c|}
\hline Sample/Level & ATV & CYG & PGN & ISTD $^{\mathbf{a}}$ \\
\hline LQC & $91.98 \pm 1.42$ & $90.75 \pm 2.05$ & $96.74 \pm 0.49$ & \\
\cline { 1 - 4 } MQC & $85.44 \pm 1.73$ & $87.62 \pm 2.71$ & $99.12 \pm 0.41$ & $85.4 \pm 2.07$ \\
\hline HQC & $87.08 \pm 2.30$ & $83.21 \pm 2.33$ & $96.70 \pm 0.91$ & $97.52 \pm 1.39$ \\
\hline Mean Recovery & $88.17 \pm 3.40$ & $87.19 \pm 3.79$ & \\
\hline a $(n=18)$
\end{tabular}

tively. The mean recovery of ATV, CYG and PGN were found to be $88.17 \pm 3.40,87.19 \pm 3.79$ and $97.52 \pm$ $1.39 \%$ respectively in human plasma whereas the ISTD recovery was $85.4 \pm 2.07 \%$. Recoveries for all three analytes along with ISTD were found consistent (Table 3).

\section{Stability studies}

The stock solutions of ATV, CYG, PGN and ISTD were found stable at room temperature $\left(25^{\circ} \mathrm{C}\right)$ for $6 \mathrm{~h}$ with mean percentage change for each analyte less than $10 \%$. There was no significant change observed in concentrations of ATV, CYG and PGN in matrix, when tested for bench top stability for $10 \mathrm{~h}$, freeze thaw stability over 3 cycles and long term stability for 90 days. The mean percentage change for each analyte at LQC and HQC level for said stability conditions was found to be less than $\pm 10 \%$ shown in (Table $4 \mathrm{a}, 4 \mathrm{~b}$ and $4 \mathrm{c}$ ) for ATV, CYG and PGN in human plasma respectively.

\section{CONCLUSION}

The objective of present study was to develop a HPLC method for the simultaneous estimation of Atovaquone, Proguanil and its active metabolite Cycloguanil in human plasma. In the present study, method was optimized in terms of chromatographic parameter and extraction of drug from the biological matrix. The developed method was validated as per US FDA guideline to prove its efficiency. The proposed method was found to be highly accurate and precise with good and consistent recovery of all analytes. The method was validated by evaluating linearity, accuracy, precision, limit of quantification and stability and found to be acceptable in terms of its predetermined acceptance criteria according to the US FDA guideline.

The method has shown acceptable precision, accuracy and adequate sensitivity and thus can be of use in the clinical studies.

\begin{tabular}{|c|c|c|c|c|c|c|}
\hline \multirow[t]{2}{*}{ Stability } & \multirow[t]{2}{*}{ Spiked conc. } & \multicolumn{2}{|c|}{$\begin{array}{c}\text { Calculated conc (comparison } \\
\text { sample) }\end{array}$} & \multicolumn{2}{|c|}{$\begin{array}{c}\text { Calculated conc (Stability } \\
\text { sample) }\end{array}$} & \multirow[t]{2}{*}{ Mean \% Change } \\
\hline & & Mean \pm SD & $\% \mathrm{CV}$ & Mean \pm SD & $\% \mathrm{CV}$ & \\
\hline \multirow[t]{2}{*}{ Bench top } & 281.25 & $301.58 \pm 5.73$ & 1.90 & $297.31 \pm 11.58$ & 3.90 & -1.42 \\
\hline & 5400.00 & $5522.57 \pm 87.42$ & 1.58 & $\begin{array}{l}5289.41 \pm \\
307.85\end{array}$ & 5.28 & -4.22 \\
\hline \multirow{2}{*}{$\begin{array}{l}\text { Freeze and } \\
\text { Thaw }\end{array}$} & 281.25 & $302.61 \pm 4.56$ & 1.51 & $288.07 \pm 7.47$ & 2.59 & -4.80 \\
\hline & 5400.00 & $5518.07 \pm 88.63$ & 1.61 & $\begin{array}{l}5201.39 \pm \\
247.15\end{array}$ & 4.75 & -5.74 \\
\hline \multirow[t]{2}{*}{ Long term } & 281.25 & $281.97 \pm 7.63$ & 2.71 & $266.76 \pm 9.79$ & 3.67 & -5.39 \\
\hline & 5400.00 & $5577.06 \pm 42.32$ & 0.76 & $5457.66 \pm 52.71$ & 0.97 & -2.14 \\
\hline
\end{tabular}

\begin{tabular}{|c|c|c|c|c|c|c|}
\hline \multirow[t]{2}{*}{ Stability } & \multirow[t]{2}{*}{ Spiked conc. } & \multicolumn{2}{|c|}{$\begin{array}{c}\text { Calculated conc (comparison } \\
\text { sample) }\end{array}$} & \multicolumn{2}{|c|}{$\begin{array}{c}\text { Calculated conc (Stability } \\
\text { sample) }\end{array}$} & \multirow[t]{2}{*}{ Mean \% Change } \\
\hline & & Mean \pm SD & $\% \mathrm{CV}$ & Mean \pm SD & $\% \mathrm{CV}$ & \\
\hline \multirow[t]{2}{*}{ Bench top } & 10.50 & $10.95 \pm 0.70$ & 6.41 & $10.71 \pm 0.44$ & 4.16 & -2.17 \\
\hline & 201.60 & $207.76 \pm 4.71$ & 2.27 & $199.97 \pm 8.68$ & 4.34 & -3.75 \\
\hline \multirow{2}{*}{$\begin{array}{l}\text { Freeze and } \\
\text { Thaw }\end{array}$} & 10.50 & $10.96 \pm 0.70$ & 6.36 & $10.24 \pm 0.80$ & 7.82 & -6.50 \\
\hline & 201.60 & $206.31 \pm 3.56$ & 1.72 & $196.59 \pm 9.42$ & 4.79 & -4.71 \\
\hline \multirow[t]{2}{*}{ Long term } & 10.50 & $10.61 \pm 0.57$ & 5.41 & $10.11 \pm 0.41$ & 4.10 & -4.71 \\
\hline & 201.60 & $204.49 \pm 5.29$ & 2.59 & $202.69 \pm 3.18$ & 1.57 & -0.88 \\
\hline
\end{tabular}




\begin{tabular}{|c|c|c|c|c|c|c|}
\hline \multirow[t]{2}{*}{ Stability } & \multirow[t]{2}{*}{ Spiked conc } & \multicolumn{2}{|c|}{$\begin{array}{c}\text { Calculated conc (comparison } \\
\text { sample) }\end{array}$} & \multicolumn{2}{|c|}{ Calculated conc (Stability sample) } & \multirow[t]{2}{*}{$\begin{array}{l}\text { Mean \% } \\
\text { Change }\end{array}$} \\
\hline & & Mean \pm SD & $\% \mathrm{CV}$ & Mean \pm SD & $\% \mathrm{CV}$ & \\
\hline \multirow[t]{2}{*}{ Bench top } & 21.09 & $21.15 \pm 0.78$ & 3.70 & $20.72 \pm 1.22$ & 5.89 & -2.05 \\
\hline & 405.00 & $416.41 \pm 16.70$ & 4.01 & $404.09 \pm 20.15$ & 4.99 & -2.96 \\
\hline \multirow{2}{*}{$\begin{array}{l}\text { Freeze and } \\
\text { Thaw }\end{array}$} & 21.09 & $21.12 \pm 0.79$ & 3.73 & $20.29 \pm 0.63$ & 3.10 & -3.94 \\
\hline & 405.00 & $416.41 \pm 16.70$ & 4.01 & $392.11 \pm 17.33$ & 4.42 & -5.83 \\
\hline \multirow[t]{2}{*}{ Long term } & 21.09 & $21.77 \pm 1.06$ & 4.89 & $19.91 \pm 0.80$ & 4.03 & -8.55 \\
\hline & 405.00 & $416.29 \pm 11.47$ & 2.75 & $398.91 \pm 5.35$ & 1.34 & -4.17 \\
\hline
\end{tabular}

The developed method has advantage for simultaneous estimation of Atovaquone, Proguanil and its active metabolite Cycloguanil in human plasma which can be used by common laboratories for various purposes like bioavailability and bioequivalence studies, drug-drug interaction studies etc.

\section{ACKNOWLEDGEMENT}

Authors acknowledges for Bioanalytical department of Ecron Acunova, Manipal and Dept of Science and Technology, Govt of India, under FIST scheme.

\section{REFERENCES}

1. Breman J, Alilio M, White NJ, Kumar A, Valecha N, Jain T, et al. Burden of malaria in India: retrospective and prospective view. Am J Trop Med Hyg. 2007; 77(6): S69-S78.

2. Blanchard TJ MD, Hunt-Cooke A, Edwards G, Hutchinson DB, Benjamin S, Chiodini PL. Multiresistant falciparum malaria cured using Atovaquone and Proguanil. Trans R Soc Trop Med Hyg. 1994; 88(6): 693.

3. Sabchareon A, Attanath P, Phanuaksook P, Chanthavanich P, Poonpanich $\mathrm{Y}$, Mookmanee D, et al. Efficacy and pharmacokinetics of Atovaquone and Proguanil in children with multidrug-resistant Plasmodium falciparum malaria. Trans R Soc Trop Med Hyg. 1998; 92(2): 201-6.

4. Canfield C, Pudney M, Gutteridge W. Interactions of Atovaquone with other antimalarial drugs against Plasmodium falciparum in vitro. Exp Parasitol. 1995; 80(3): 373-81

5. Looareesuwan S, Wilairatana P, Chalermarut K, Rattanapong Y, Canfield CJ, Hutchinson DB. Efficacy and safety of Atovaquone/Proguanil compared with mefloquine for treatment of acute Plasmodium falciparum malaria in Thailand. Am J Trop Med Hyg. 1999; 60(4):526-32.
6. Mulenga M, Sukwa TY, Canfield CJ, Hutchinson DB. Atovaquone and Proguanil versus pyrimethamine/sulfadoxine for the treatment of acute falciparum malaria in Zambia. Clin Ther. 1999; 21(5): 841-52.

7. Overbosch D, Schilthuis H, Bienzle U, Behrens RH, Kain KC, Clarke PD, et al. Atovaquone-Proguanil versus mefloquine for malaria prophylaxis in nonimmune travelers: results from a randomized, double-blind study. Clin Infect Dis. 2001; 33(7): 1015-21.

8. Bergqvist $\mathrm{Y}$, Hopstadius C. Simultaneous separation of Atovaquone, Proguanil and its metabolites on a mixed mode high-performance liquid chromatographic column. J Chromatogr B Biomed Sci Appl. 2000; 741(2): 189-93.

9. Lindegarth N, Funding L, Bergqvist Y. Automated solid-phase extraction method for the determination of Atovaquone in capillary blood applied onto sampling paper by rapid high-performance liquid chromatography. J Chromatogr B Biomed Sci Appl. 2001; 758(2):137-44.

10. Lejeune D, Souletie I, Houze S, Le bricon T, Le bras J, Gourmel B, et al. Simultaneous determination of monodesethylchloroquine, chloroquine, Cycloguanil and Proguanil on dried blood spots by reverse-phase liquid chromatography. J Pharm Biomed Anal. 2007; 43(3): 1106-15.

11. Bergqvist $Y$, Funding L, Kaneko A, Krysén B, Leek T. Improved method for the simultaneous determination of Proguanil and its metabolites by highperformance liquid chromatography and solid-phase extraction of $100 \mu \mathrm{l}$ capillary blood samples dried on sampling paper. J Chromatogr B Biomed Sci Appl. 1998; 719(1): 141-9.

12. Scott H, Edstein M, Veenendaal J, Rieckmann K. A sensitive bioassay for serum Cycloguanil using Plasmodium falciparum in vitro. Int $\mathrm{J}$ Parasitol. 1988; 18(5): 605-9.

13. Leveque NL, Charman WN, Chiu FC. Sensitive method for the quantitative determination of Proguanil and its metabolites in rat blood and plasma by liquid chromatography-mass spectrometry. J Chromatogr B. 2006; 830(2): 314-21.

14. FDAC. Guidance for industry: bioanalytical method validation. US Department of Health and Human Services. Food and Drug Administration, Center for Drug Evaluation and Research (CDER), Center for Veterinary Medicine (CV). 2001. Available from: "http://www. fda. gov/cder/guidance/index. 